to $\mathrm{SAD}$ products could be observed, the relative decrease could indicate a positive effect.

The simulation study indicated that specific design features such as yellow background colour, Tall Man lettering and consistent design improved safety in the medication process. However, the new label design is complex implying a potential for misinterpretation of the features if the users are not familiar with the design.

Conclusions The effect of the new design depends on several factors such as the user's knowledge of the design, the complexity of the design and the context of use. Errors related to misinterpretation of labels remains a problem and research into good label design remains a relevant topic.

No conflict of interest.

\section{GRP-071 EVALUATION OF THE PRESCRIPTION OF INTRAVENOUS NON-STEROIDAL ANTI-INFLAMMATORY DRUGS COMPARED TO THE RECOMMENDATIONS OF THE SUMMARY OF PRODUCT CHARACTERISTICS}

doi:10.1136/ejhpharm-2013-000276.071

C Salazar Saldebenito, MJ De Dios Garcia, M Alcalde Rodrigo, C Gonzalez-Guerrero, JB Montoro Ronsano, M Munné Garcia, I Cardona Pascual. Hospital Universitari Vall d'Hebron, Pharmacy, Barcelona, Spain

Background Acute renal failure is a side effect of NSAIDs.

Purpose To assess the appropriateness of the intravenous prescription of dexketoprofen according to the dosage specifications depending on renal function following the recommendations of the Summary of Product Characteristics.

Materials and Methods An observational, retrospective study that analysed dexketoprofen prescriptions in surgical patients admitted to a tertiary hospital from January-September 2011. The estimated glomerular filtration rate (eGF) was calculated by the CKD-EPI formula, of reference in the hospital.

The Summary of Product Characteristics advises using the following posology for dexketoprofen:

- $150 \mathrm{mg}$ maximum daily dose for a maximum duration of 48 hours.

- In patients with renal impairment:

- $\mathrm{GF}<50 \mathrm{~mL} / \mathrm{min}$ : administration contraindicated

- GF $50-80 \mathrm{~mL} / \mathrm{min}: 25 \mathrm{mg} / 12 \mathrm{~h}$. Maximum: $50 \mathrm{mg}$ daily.

- $\mathrm{GF}>80 \mathrm{~mL} / \mathrm{min}$ : No dosage adjustment required.

Results Prescriptions from 1946 patients were analysed. Of the patients, $54.3 \%$ were male and $45.7 \%$ female, with a mean age of 59.8 years $(17-103)$. The mean serum creatinine levels were $0.84 \mathrm{mg} / \mathrm{dL} \pm 0.43$ and the mean eGF from the CKD-EPI calculation was $83.05 \pm 26.17 \mathrm{~mL} / \mathrm{min} / 1.73 \mathrm{~m}^{2}$.

In $58 \%$ of the admissions the drug was not prescribed correctly. Of these:

- 270 patients were prescribed dexketoprofen when the eFG was less than $50 \mathrm{~mL} / \mathrm{min} / 1.73 \mathrm{~m}^{2}$;

- 550 of them had an unadjusted prescription with an eFG $50-80 \mathrm{~mL} / \mathrm{min} / 1.73 \mathrm{~m}^{2}$

- 370 patients with an $\mathrm{eGF}>80 \mathrm{~mL} / \mathrm{min} / 1.73 \mathrm{~m}^{2}$ were prescribed NSAIDs for longer than $48 \mathrm{~h}$.

Conclusions $58 \%$ of the intravenous NSAID prescriptions did not conform to the SPC recommendations. Due to this fact and in order to prevent renal toxicity it is recommended:

1. To establish protocols for pain management during hospitalisation to limit the duration of these drugs to 48 hours and adjust the dose to the patient's renal function.

2. To enhance the proactive role of the pharmacist in individualised patient monitoring.

No conflict of interest.

\section{GRP-072 EXPOSURE TO ANTINEOPLASTIC AGENTS IN ONCOLOGY DEPARTMENTS: PRACTISE SURVEY AND INFORMATION TO THE PERSONNEL OF THREE ONCOLOGY DEPARTMENTS}

doi:10.1136/ejhpharm-2013-000276.072

${ }^{1}$ S Slimano, ${ }^{2} \mathrm{MC}$ Mourad, 'L De Mestier, ${ }^{2} \mathrm{C}$ Regouby, ${ }^{1} \mathrm{O}$ Bouche. ${ }^{1} \mathrm{CHU}$ de Reims, Medicine Ambulatory Unit - Oncology-Hematology, Reims Cedex, France; ${ }^{2} \mathrm{CHU}$ de Reims, Pharmacy, Reims Cedex, France

Background The exposure of pharmacy technicians to antineoplastic agents (AAs) has been widely studied, but less is known about risks of exposure and awareness of nurses, nursing auxiliaries and cleaning personnel.

Purpose To evaluate the practise and the awareness of oncology nurses (ONs), nursing auxiliaries (NAs) and cleaning personnel (CP) concerning exposure to AA.

Materials and Methods Three questionnaires were distributed to ONs, NAs and CP in three oncology wards including one paediatric ward. Participants were asked 10,11 and 12 questions respectively about their practises and awareness of exposure to AAs.

Results For ONs $(n=38)$, gloves are more often worn when manipulating syringes than when manipulating infusion bags $(60.5 \%$ vs. $36.8 \%, p<0.05) .26 .3 \%$ considered themselves well informed but $97.4 \%$ thought information could be improved. $81.6 \%$ of ONs suspected that AAs had teratogenic effects and $10.5 \%$ of them thought that AAs did not have mid- or long-term toxic effects. For NAs $(n=14)$, wearing gloves while washing patients or eliminating excreta was more frequent than mask wearing $(64.3 \%$ vs. $5.3 \%$ ). $28.6 \%$ considered themselves well informed but $92.9 \%$ thought information could be improved. $85.7 \%$ of NAs suspected that AAs had teratogenic effects and $14.3 \%$ of them thought that AAs did not have mid- or long-term toxic effects. For CP $(n=10)$, $62.5 \%$ wore gloves for bed making and $80.0 \%$ for sanitation cleaning. All of them considered themselves not sufficiently informed and $90.0 \%$ thought that AAs had teratogenic effects whereas $10 \%$ of them thought that AAs did not have mid- or long-term toxic effects. All $(n=62)$ reported routine use of water and soap $(46.8 \%)$ or hydro-alcoholic solution (25.8\%) after a potential exposure to AAs. Conclusions Lack of information suggested the necessity of informing the nursing and cleaning personnel on the oncology ward in some fields. A teaching session was arranged by department.

No conflict of interest.

\section{GRP-073 FAILURE MODE AND EFFECT ANALYSIS IN IMPROVING THE SAFETY OF THE CHEMOTHERAPY PROCESS}

doi:10.1136/ejhpharm-2013-000276.073

B Hernandez, C Bravo, MJ Esteban, E García, B Candel, M García, Y Castellanos, J Letellez, J Sierra, FJ Farfán. Hospital de Fuenlabrada, Pharmacy, Madrid, Spain

Background Medication errors in chemotherapy have a high potential to cause harm. Errors may occur during different steps of the medication process.

Failure Mode and Effect Analysis (FMEA) is a proactive risk assessment method that enables potential risks to be identified and prioritises actions to improve safety.

Purpose To apply FMEA methodology to the chemotherapy process: prescribing, pharmaceutical validation, compounding and dispensing.

Materials and Methods Prospective study, in a tertiary level hospital, using the FMEA technique developed by the Veterans Affairs Healthcare System for the chemotherapy process. An interdisciplinary working group was created and meetings held over three months. Processes and subprocesses were described; potential failure modes and possible causes were identified. Main sources used were brainstorming and cause-effect-diagramming. For each failure 